\title{
$\beta$-elemene enhances anticancer bone neoplasms efficacy of paclitaxel through regulation of GPR124 in bone neoplasms cells
}

\author{
ZONGZE WANG ${ }^{1},{\text { YING } \mathrm{LI}^{2} \text {, FENGXIN ZHOU }}^{1}$, ZHE PIAO $^{1}$ and JIAN HAO ${ }^{1}$ \\ ${ }^{1}$ Department of Orthopedics, Nankai Hospital of Tianjin, Tianjin 300100; \\ ${ }^{2}$ Renal Department of Internal Medicine, The Second Hospital of Tianjin Medical University, Tianjin 300211, P.R. China
}

Received March 25, 2017; Accepted May 24, 2018

DOI: $10.3892 / \mathrm{ol} .2018 .8909$

\begin{abstract}
The purpose of the present study was to investigate the anticancer effects of $\beta$-elemene and paclitaxel for bone neoplasms. MTT assay, reverse transcription-quantitative polymerase chain reaction, western blotting, flow cytometry and immunostaining were used to analyze the combined effects of $\beta$-elemene and paclitaxel both in vitro and in vivo. The results demonstrated that combined treatment of $\beta$-elemene and paclitaxel ( $\beta$-elemene-paclitaxel) significantly inhibited growth and aggressiveness of $\mathrm{U}-2 \mathrm{OS}$ cells compared with either $\beta$-elemene or paclitaxel treatment alone. It was demonstrated that $\beta$-elemene promoted paclitaxel-induced apoptosis of U-2OS cells. Anti-apoptosis B-cell lymphoma (Bcl)-2 and Bcl-w genes were downregulated and pro-apoptotic Bcl-2-associated agonist of cell death and caspase- 3 genes were upregulated in $\mathrm{U}-2 \mathrm{OS}$ cells following treatment with $\beta$-elemene-paclitaxel. Treatment of $\beta$-elemene-paclitaxel arrested the cell cycle and decreased cyclin-dependent kinase, cyclin-B1, P21 and P27 expression levels and decreased resistant genes alterations of ATP binding cassette subfamily B member 1, LDL receptor related protein and TS in U-2OS cells. Results demonstrated that $\beta$-elemene-paclitaxel decreased $\mathrm{G}$-protein coupled receptor 124 (GPR124), vascular endothelial growth factor receptor, matrix metallopeptidase (MMP)-3, MMP-9 expression levels and increased endostatin, TIMP metallopeptidase inhibitor (TIMP)-1, TIMP-2 expression in U-2OS cells. In vivo assay demonstrated that $\beta$-elemene-paclitaxel treatment inhibited tumor growth of $\mathrm{BALB} / \mathrm{c}-\mathrm{nu} / \mathrm{nu}$ nude mice and prolonged survival rate of tumor-bearing mice. Immunostaining demonstrated that $\beta$-elemene-paclitaxel treatment increased apoptotic bodies, GPR124 and increased endostatin, TIMP-1 and TIMP-2
\end{abstract}

Correspondence to: Professor Zongze Wang, Department of Orthopedics, Nankai Hospital of Tianjin, 6 Changjiang Road, Tianjin 300100, P.R. China

E-mail: wangzongzeprof@163.com

Key words: bone neoplasms, $\beta$-elemene, paclitaxel apoptosis, GPR124 expression in tumor tissues. In conclusion, these results suggest that the combined treatment of $\beta$-elemene-paclitaxel is more effective at inhibiting bone neoplasm growth than $\beta$-elemene or paclitaxel single treatment GPR124.

\section{Introduction}

Bone neoplasm is typical systemic malignant disease, which mainly leads to common symptoms of bone and joint pain and fatigue in patients $(1,2)$. Osteosarcoma is the most common cancer-caused dead and the prognosis remains incompletely understand due to the paucity of effective therapeutic targets that significantly influences quality of life and mean survival rate of the patients with osteosarcoma $(3,4)$. Clinicopathological and molecular correlations explain the role of bone marrow microvessel density (MVD) and plasma angiogenic factors in myeloproliferative neoplasms and highlight the strong correlation of MVD with plasma angiogenic factors, JAK2 mutant allele burden, and bone marrow fibrosis in myeloproliferative neoplasms (5).

Paclitaxel is a secondary metabolite of taxus plant that has been reported to association with inhibition of cancer cells growth $(6,7)$. Researches have showed that paclitaxel leads to generation of tubulin and tubulin dimer, which promotes the polymerization of tubulin and the assembly of microtubule and further results in cells cycle arrest for tumor cells $(8,9)$. Previous studies have investigated the paclitaxel can significantly inhibit ovarian cancer cells growth through cyclin-dependent kinase 11 (CDK11) and inhibition of insulin-like growth factor (IGF) signaling in preclinical pancreatic cancer models $(10,11)$. Notably, paclitaxel shows antitumor activity through the interplay with apoptosis network in triple-negative breast cancer, indicating that paclitaxel has therapeutic potential for human endometrial cancer by targeting of endogenous apoptosis signaling pathway $(12,13)$.

Elemene is a new drug extracted from the activating blood circulation herbs, which presents the broad-spectrum antineoplastic, immune protection and other effects (14). In recent years, evidences have indicated that $\beta$-elemene has the effects to induce cells apoptosis and differentiation, reverses multiple drug resistance of tumor, and enhances the sensibility of combined radiotherapy and chemotherapy $(14,15)$. Interestingly, antineoplastic effects of $\beta$-elemene on prostate 
cancer cells and other types of solid tumor cells have been investigated and supported that $\beta$-elemene may act as a new potentially therapeutic drug for castration-resistant prostate cancer and other solid tumors (16).

Therefore, the purpose of this study investigated the combined anticancer effects of $\beta$-elemene and paclitaxel on bone neoplasms. We analyzed bone neoplasm cells growth, cells cycle, apoptosis and in vivo growth after treatment with $\beta$-elemene-paclitaxel. We also focused the important function of gene G-protein coupled receptor 124 (GPR124) in $\beta$-elemene-paclitaxel-inhibited growth of bone neoplasms.

\section{Materials and methods}

Ethics statement. The present study was carried out in strict accordance with the recommendations in the Guide for the Care and Use of Laboratory Animals. All experimental protocols and animals were performed in accordance with National Institutes of Health and approved by the Ethics Committee of the Nankai Hospital of Tianjin.

Cell line. U-2OS cells were purchased from American Type Culture Collection (ATCC, Manassas, VA, USA). The cells were cultured using RPMI1640 medium (Biosera, Nuaille, France) with $10 \% \mathrm{FBS}$ at $37^{\circ} \mathrm{C}$ in $\mathrm{CO}_{2}$ incubator (5\%).

MTT assay. U-2OS cells were incubated with $\beta$-elemene $(100 \mathrm{mg} / \mathrm{ml})$, paclitaxel $(20 \mathrm{mg} / \mathrm{ml})$ or combined treatment in 96-well plates for 24, 48 and $72 \mathrm{~h}$ in triplicate for each condition with PBS as control in $5 \% \mathrm{CO}_{2}$ at $37^{\circ} \mathrm{C}$ for $24 \mathrm{~h}$. Subsequently, the control group was added with MTT solution after the removal of supernatant thereafter incubated for $4 \mathrm{~h}$. In the blank control group $100 \mu \mathrm{l}$ DMSO was added after removal of the supernatant after that shocked for $30 \mathrm{~min}$, the enzyme standard instrument were used to detect at $570 \mathrm{~nm}$ (680 Microplate reader; Bio-Rad Laboratories, Inc., Hercules, CA, USA).

Flow cytometry assay. U-2OS cells were grown at $37^{\circ} \mathrm{C}$ with $5 \% \mathrm{CO}_{2}$ until $90 \%$ confluence was formatted. Cells were then incubated with $\beta$-elemene $(100 \mathrm{mg} / \mathrm{ml})$, paclitaxel $(20 \mathrm{mg} / \mathrm{ml})$ or combined treatment for $24 \mathrm{~h}$. After incubation, the tumor cells were trypsinized and collected. The cells were then washed in cold PBS, adjusted to $1 \times 10^{6}$ cells $/ \mathrm{ml}$ with $\mathrm{PBS}$, labeled with Annexin V-FITC and PI (Annexin V-FITC kit), and analyzed with a FACScan flow cytometer (both BD Biosciences, Franklin Lakes, NJ, USA). The treatments were performed in triplicate, and the percentage of labeled cells undergoing apoptosis in each group was determined and calculated.

Reverse transcription-quantitative polymerase chain reaction $(R T-q P C R)$ assay. Total RNA in U-2OS cells was extracted using RNAzol, and DNase RNase-free was adopted to digest total RNA at $37^{\circ} \mathrm{C}$ for $15 \mathrm{~min}$, and then RNeasy kit to purify RNA to adjust its concentration to $1 \mu \mathrm{g} / \mu \mathrm{l}$. The $2 \mu \mathrm{g}$ RNA was used as the template to synthetize cDNA by reacting with reverse transcriptase at $37^{\circ} \mathrm{C}$ for $120 \mathrm{~min}$, at $99^{\circ} \mathrm{C}$ for $4 \mathrm{~min}$, and at $4^{\circ} \mathrm{C}$ for $3 \mathrm{~min}$ respectively. Followed by, reverse transcription-polymerase chain reaction method
Table I. Sequences of primers were used in this study.

Gene

name

Sequence

GPR124 Reverse: 5'-GGTCGTTCTACTGGGCTGATT-3' Forward: 5'-AGCAAGAGGGGATTTCACAAT-3'

TIMP-1 Forward: 5'-GTCAGTGAGAAGCAAGTCGA-3' Reverse: 5'-ATGTTCTTCTCTGTGACCCA-3'

TIMP-2 Forward: 5'-TGG GGACACCAGAAGTCAAC-3' Reverse: 5'-TTTTCAGAGCCTTGGAGGAG-3'

MMP-3 Reverse: 5'-CTTCTTCAAGGACCGGTCA-3' Forward: 5'-GCTGGCTGAGTACCAGTA-3'

MMP-9 Reverse: 5'-TGGGCTACGTGACCTATGAC-3' Forward: 5'-GCCCAGCCCACCTCCACTCC-3'

VEGF Reverse:5'-GCACCCATGGCAGAAGGAGGAG-3' Forward: 5'-GTGCTGACGCTAACTGACC-3'

Endostatin Forward: 5'-ATGCACAGCCACCGCGACTT-3' Reverse:5'-CTTCATGACTGCCTCCAAGTAG-3'

Bcl-2 Forward: 5'-CTCAGCCAGCCAGTGACATA-3' Reverse: 5'-CCGTGCTCCAGATACAT-3'

Bcl-w Forward: 5'-AGAGTGGACCACACTGCGC-3' Reverse: 5'-ACATCCCAACGGTCATCGTA-3'

Bax Reverse: 5'-GGAGGGGATCAGTATATACA-3' Forward: 5'-GAAGATGGAGAGATGG-3'

Caspase-3 Reverse: 5'-CTGTGAGATCACTGGCTTTG-3' Forward: 5'-TTGGAGGGAACAGACGAG-3'

CDK1 Reverse: 5'-ACAGTGCATCATCGCTGTTC-3' Forward: 5'-CCGGAGAGGAGACTTCACAG-3'

Cyclin-B1 Reverse: 5'-GAAAGCATCCAGCAATAGGC-3' Forward: 5'-TAAGGAAGCCTGGAGCACAG-3'

P27 Reverse: 5'-CATGGTGAAACCCCGTCTCTA-3' Forward: 5'-GCCTCAGCCTCCCGAGTAG-3'

MDR1 Reverse: 5'-GGGCAGAATCTTTCCACCA-3' Forward:5'-TTAAATGTATACCCAAAGACAA-3'

LRP Reverse: 5'-CGAATGGGTGTTTTCACATATG-3' Forward: 5'-CTTCAATTGTATTCAGGATGG-3'

TS Reverse: 5'-CACCCTCAATATTTGGAA-3' Forward:5'-CCGTTGTTGTAGGACTAATGAA-3'

$\beta$-actin Reverse: 5'-CGGAGTCAACGGATTTGGTC-3' Forward: 5'-AGCCTTCTCCATGGTCGTGA-3'

GPR124, G-protein coupled receptor 124; TIMP, TIMP metallopeptidase inhibitor; MMP, matrix metallopeptidase; VEGF, vascular endothelial growth factor; Bcl, B-cell lymphoma; Bax, Bcl-2 associated $\mathrm{X}$, apoptosis regulator; $\mathrm{CDK} 1$, cyclin dependent kinase 1; MDR1, ATP binding cassette subfamily B member 1; LRP, LDL receptor related protein.

was adopted to amplify the gene expression of GPR124, TIMP metallopeptidase inhibitor (TIMP)-1, TIMP-2, matrix metallopeptidase (MMP)-2, MMP-9, vascular endothelial growth factor (VEGF), endostatin, CDK1, cyclin-B1, P27, 

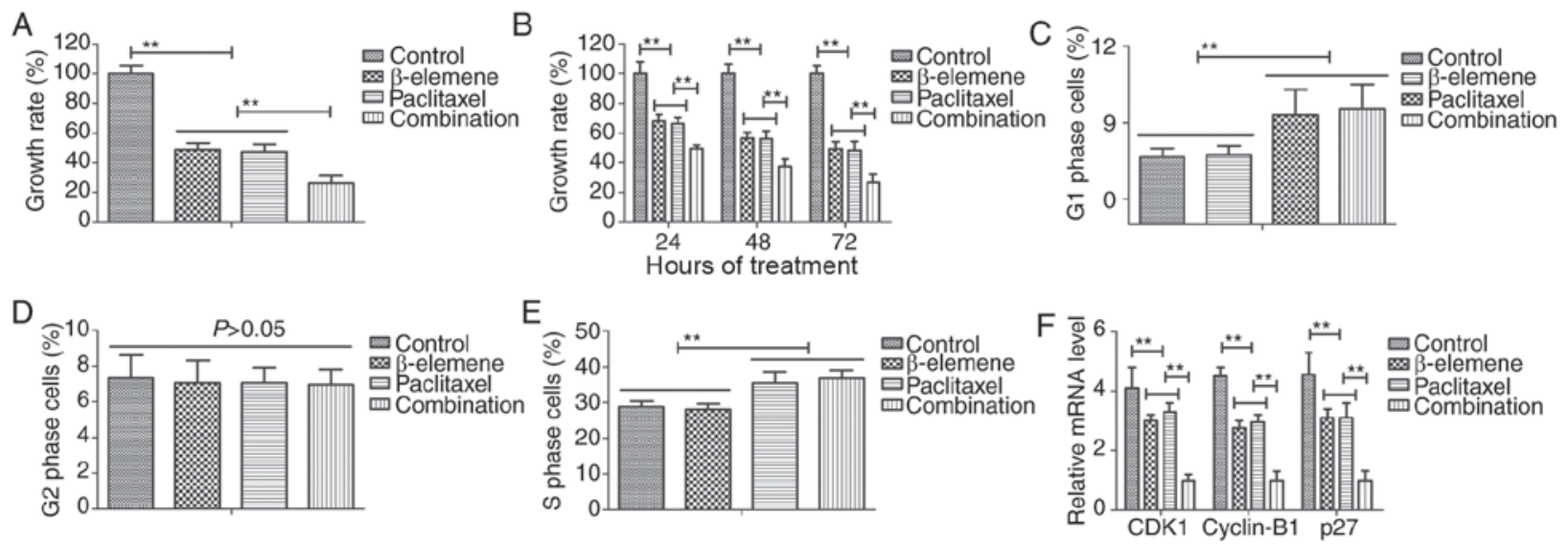

Figure 1. Treatment of $\beta$-elemene-paclitaxel inhibits growth and arrests cell cycle of U-2OS cells. (A) Combined treatment of $\beta$-elemene (100 mg/ml) and paclitaxel $(20 \mathrm{mg} / \mathrm{ml})$ significantly inhibits growth of U-2OS cells. (B) Combined treatment of $\beta$-elemene $(100 \mathrm{mg} / \mathrm{ml})$ and paclitaxel $(20 \mathrm{mg} / \mathrm{ml}) \mathrm{suppresses}$ growth of U-2OS cells in time-dependent manner. (C-E) Treatment of (C) $\beta$-elemene (D) paclitaxel and $\beta$-elemene-paclitaxel (E) arrested U-2OS cells cycle at G1 and S, G1, S phase respectively. (F) Combined treatment of $\beta$-elemene-paclitaxel decreases gene CDK1, cyclin-B1 and P27 expression levels in U-2OS cells, ${ }^{* *} \mathrm{P}<0.01$. CDK1, cyclin-dependent kinase 11.

MDR1, LRP and TS (Table I) to determine the transcription level of mRNA, and $\beta$-actin was used as the housekeeping genes of internal control group. Eventually, agarose electrophoresis with $1 \%$ ethidium bromide was adopted to check PCR amplified products. Relative mRNA expression changes were calculated by $2-\Delta \Delta \mathrm{Ct}$. The results are expressed as the $\mathrm{n}$-fold way compared to control.

Cells invasion and migration assays. U-2OS cells were grown at $37^{\circ} \mathrm{C}$ with $5 \% \mathrm{CO}_{2}$ until $90 \%$ confluence was formatted. U-2OS cells were then incubated with $\beta$-elemene $(100 \mathrm{mg} / \mathrm{ml})$, paclitaxel $(20 \mathrm{mg} / \mathrm{ml})$ or combined treatment for $24 \mathrm{~h}$. For invasion assay, U-2OS cells were suspended as a density of $1 \times 10^{5}$ in $500 \mu \mathrm{l}$ in serum-free RPMI 1640. Cells were subjected to the tops of BD BioCoat Matrigel Invasion Chambers (BD Biosciences) according to the manufacturer's instructions. For migration assay, cells were subjected to a control insert (BD Biosciences) instead of a Matrigel Invasion Chamber. The tumor cells migration and invasion were counted in at least three randomly stain-field microscope every membrane.

Western blot analysis. U-2OS cells were then incubated with $\beta$-elemene $(100 \mathrm{mg} / \mathrm{ml})$, paclitaxel $(20 \mathrm{mg} / \mathrm{ml})$ or combined treatment for $24 \mathrm{~h}$. Cells were collected and lysed in RIPA buffer (M-PER reagent for the cells and T-PER reagent for the tissues, Thermo Scientific) followed homogenized at $4^{\circ} \mathrm{C}$ for $10 \mathrm{~min}$. A total of $20 \mu \mathrm{g}$ protein extracts was electrophoresed on $12.5 \%$ polyacrylamide gradient gels and then transferred to nitrocellulose membranes. The membranes were incubated in blocking buffer (5\% milk) prior to incubation with primary antibodies at $4^{\circ} \mathrm{C}$ overnight. The primary rabbit anti-mouse antibodies used in the immunoblotting assays were: metastasis gene metastasis-associated protein (MTA) 3 (1:200; ab176346), MMP-3 (1:1,000; ab53015), MMP-9 (1:1,000; ab38898), VEGF (1:500; ab11938), GRP124 (1:500; ab67280), endostatin (1:500; ab64569), TIMP-1 (1:1,000; ab38978), TIMP-2 (1:500; ab180630), and $\beta$-actin (1:500; ab8226; all Abcam, Cambridge, UK). Horseradish peroxidase (HRP)-conjugated anti-rabbit
IgG (Bio-Rad Laboratories, Inc.) was used at a 1:5,000 dilution and detected using a Western Blotting Luminol Reagent.

Animals study. 6-8 weeks ( $\mathrm{n}=60)$ old male $\mathrm{BALB} / \mathrm{c}-\mathrm{nu} / \mathrm{nu}$ nude mice were purchased from Beijing University and housed in a temperature-controlled facility at $23 \pm 1^{\circ} \mathrm{C}$ and relative humidity of $50 \pm 5 \%$ with a 12 -h light/dark cycle. Cultured $\mathrm{U}-2 \mathrm{OS}$ cells $\left(5 \times 10^{7}\right)$ in $20 \mu \mathrm{l}$ PBS were subcutaneously injected into the right forelimb of nude mouse under aseptic condition. Mice were divided into four groups $(\mathrm{n}=10$ in each group) and received treatment of $1.0 \mathrm{mg} / \mathrm{kg} \beta$-elemene, $1.0 \mathrm{mg} / \mathrm{kg}$ paclitaxel and combined treatment $(1.0 \mathrm{mg} / \mathrm{kg}$ $\beta$-elemene $+1.0 \mathrm{mg} / \mathrm{kg}$ paclitaxel) or PBS by intravenous injection. Treatments were initiated on day 3 after tumor implantation (diameter, 5-6 mm). The treatment was continued 7 times once time a day. The tumor volumes were calculated according to the formula, $\mathrm{V}=0.5 \mathrm{xa}^{2} \mathrm{xb}$, calculate the relative tumor volume and draw growth curve [(a) short diameter and (b) the long diameter of tumor with vernier caliper].

Immunohistochemical staining. Paraffin-embedded tumor tissue sections were prepared and epitope retrieval was performed for further analysis. The paraffin sections were treated with hydrogen peroxide (3\%) for $15 \mathrm{~min}$ and subsequently were blocked by a regular blocking solution for $20 \mathrm{~min}$ $37^{\circ} \mathrm{C}$. The sections were incubated rabbit anti-mouse GRP124 (1:500; ab67280), VEGF (1:500; ab11938), and endostatin (1:500; ab64569; all Abcam) respectively, at $4^{\circ} \mathrm{C}$ for $12 \mathrm{~h}$ after blocking. All sections were washed three times and incubated with HRP-conjugated anti-rabbit IgG (Bio-Rad Laboratories, Inc.) was used at a $1: 10,000$ dilution for $1 \mathrm{~h}$ at $37^{\circ} \mathrm{C}$. For apoptotic cells in tumor tissues, tumor sections were stained with TUNEL according to previous report (17).

Statistical analysis. The experiments data were expressed as mean \pm standard (SD) deviation. The significant difference $(\mathrm{P}<0.05)$ of data of different groups were calculated using Duncan's multiple range test using SAS version 9.2 (SAS Institute Inc., Cary, NC, USA). 

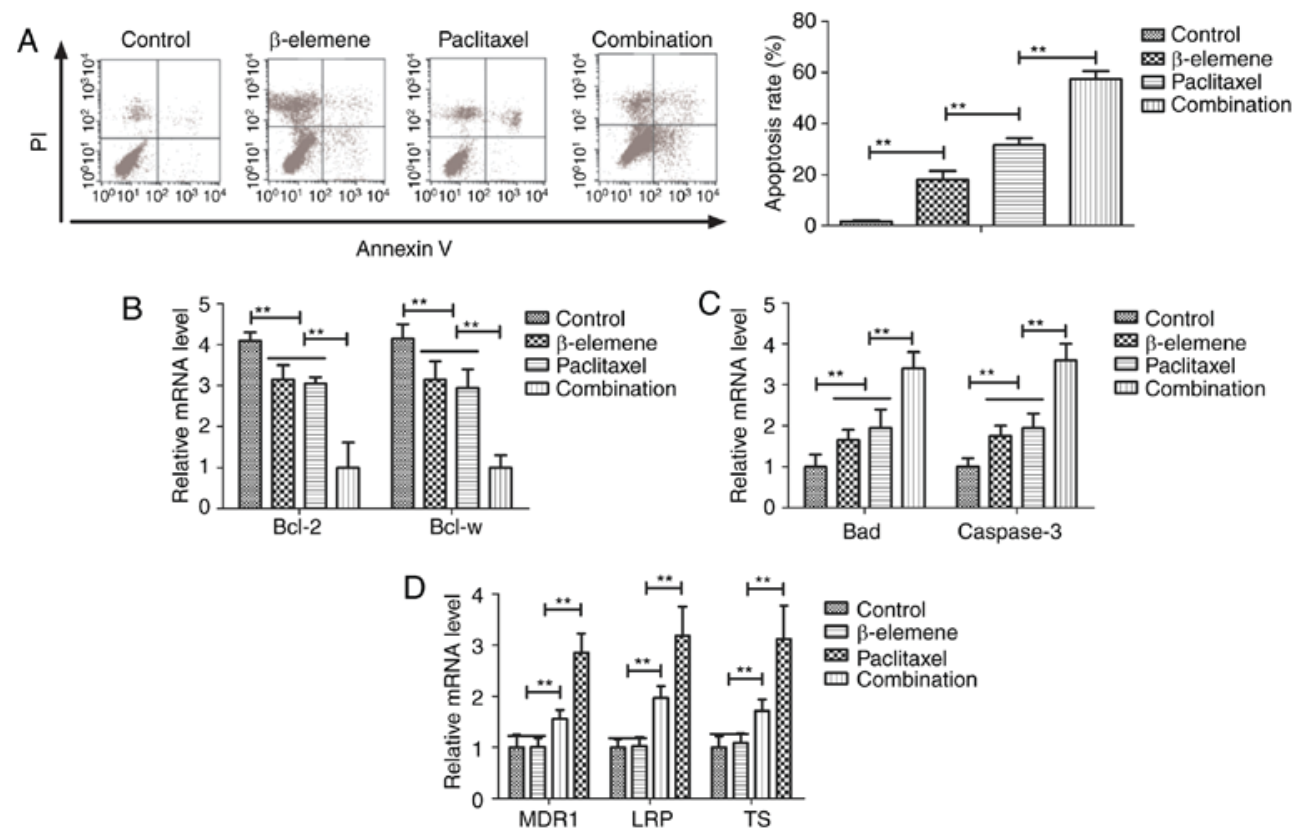

Figure 2. Treatment of $\beta$-elemene-paclitaxel induces apoptosis of U-2OS cells. (A) Combined treatment of $\beta$-elemene-paclitaxel induces apoptosis of U-2OS cells. (B) Combined treatment of $\beta$-elemene-paclitaxel decreases expression of Bcl-2 and Bcl-w anti-apoptosis genes compared to $\beta$-elemene and paclitaxel group. (C) Combined treatment of $\beta$-elemene-paclitaxel decreases expression of Bad and caspase-3 pro-apoptosis genes compared to $\beta$-elemene and paclitaxel group. (D) Combined treatment of $\beta$-elemene-paclitaxel decreases expression of MDR, LRP, TS genes compared to $\beta$-elemene and paclitaxel group, ${ }^{* *} \mathrm{P}<0.01$. Bcl, B-cell lymphoma.

\section{Results}

Treatment of $\beta$-elemene-paclitaxel on growth and cell cycle of $U-2 O S$ cells. The efficacy of $\beta$-elemene-paclitaxel on growth and cell cycle was investigated in U-2OS cells. Results demonstrated that combined treatment of $\beta$-elemene $(100 \mathrm{mg} / \mathrm{ml})$ and paclitaxel $(20 \mathrm{mg} / \mathrm{ml})$ significantly inhibited growth of U-2OS cells (Fig. 1A). Results also showed that inhibitory effects of $\beta$-elemene-paclitaxel for growth of U-2OS cells presented time-dependent manner (Fig. 1B). As shown in Fig. 1C-E, Treatment of $\beta$-elemene-paclitaxel, $\beta$-elemene and paclitaxel arrested U-2OS cells cycle at G1 and $\mathrm{S}, \mathrm{G1}, \mathrm{S}$ phase respectively. We found that decreased gene CDK1, cyclin-B1 and P27 expression levels in U-2OS cells (Fig. 1F). Collectively, these results suggest that treatment of $\beta$-elemene-paclitaxel could inhibit growth and arrests cell cycle of U-2OS cells compared to single treatment.

Treatment of $\beta$-elemene-paclitaxel on apoptosis of $U-2 O S$ cells. Efficacy of $\beta$-elemene-paclitaxel-induced apoptosis of U-2OS cells was analyzed in this study. Paclitaxel (20 $\mathrm{mg} / \mathrm{ml}$ )-induced apoptosis of U-2OS cells was promoted by $\beta$-elemene $(100 \mathrm{mg} / \mathrm{ml})$ after 24 -h incubation (Fig. $2 \mathrm{~A})$. Gene analysis demonstrated that $\beta$-elemene-paclitaxel treatment showed lower expression of B-cell lymphoma (Bcl)-2 and $\mathrm{Bcl}-\mathrm{w}$ anti-apoptosis genes compared to $\beta$-elemene and paclitaxel group (Fig. 2B). However, pro-apoptosis Bad and caspase-3 genes were markedly up-regulated in U-2OS cells by $\beta$-elemene-paclitaxel treatment (Fig. 2C). We also investigated the effects of $\beta$-elemene on drug resistant genes for paclitaxel in U-2OS cells. As shown in Fig. 2D, $\beta$-elemene decreased drug resistant genes expression levels of MDR1, LRP and TS in U-2OS cells (Fig. 2D). These results indicate that $\beta$-elemene enhances apoptosis of bone neoplasms cells induced by paclitaxel via decreasing of drug resistant genes expression.

Effects of $\beta$-elemene on drug resistant genes for paclitaxel Treatment of $\beta$-elemene-paclitaxel on migration and invasion of $U-2 O S$ cells. Anti-metastasis effects of $\beta$-elemene-paclitaxel were analyzed in U-2OS cells. As shown in Fig. 3A, B, $\beta$-elemene-paclitaxel treatment significantly inhibited migration and invasion of U-2OS cells. We showed that tumor-metastasis gene MTA3 and VEGF expression after treatment with $\beta$-elemene-paclitaxel (Fig. 3C). Western blot also confirmed the efficacy of $\beta$-elemene-paclitaxel treatment on inhibition of MTA3 and VEGF expression in U-2OS cells (Fig. 3D). These results indicate that Treatment of $\beta$-elemene-paclitaxel can efficiently inhibit migration and invasion of U-2OS cells compared to either $\beta$-elemene or paclitaxel treatment.

Treatment of $\beta$-elemene-paclitaxel on tumor angiogenesis-related gene expression in $U-2 O S$ cells. In order to analyze the inhibitory effects of treatment of $\beta$-elemene-paclitaxel, apoptosis tumor angiogenesis-related gene expression levels were detected in U-2OS cells. Results demonstrated that $\beta$-elemene-paclitaxel combination significantly decreased GPR124, MMP-3 and MMP-9 gene and protein expression levels in U-2OS cells (Fig. 4A, B). However, we showed that $\beta$-elemene-paclitaxel combination significantly increased endostatin, TIMP-1 and TIMP-2 expression in U-2OS cells compared single treatment of $\beta$-elemene and paclitaxel (Fig. 4C, D). Collectively, these results indicate that Treatment of $\beta$-elemene-paclitaxel is beneficial for controlling U-2OS cells growth by regulation of apoptosis tumor angiogenesis-related gene expression in U-2OS cells. 

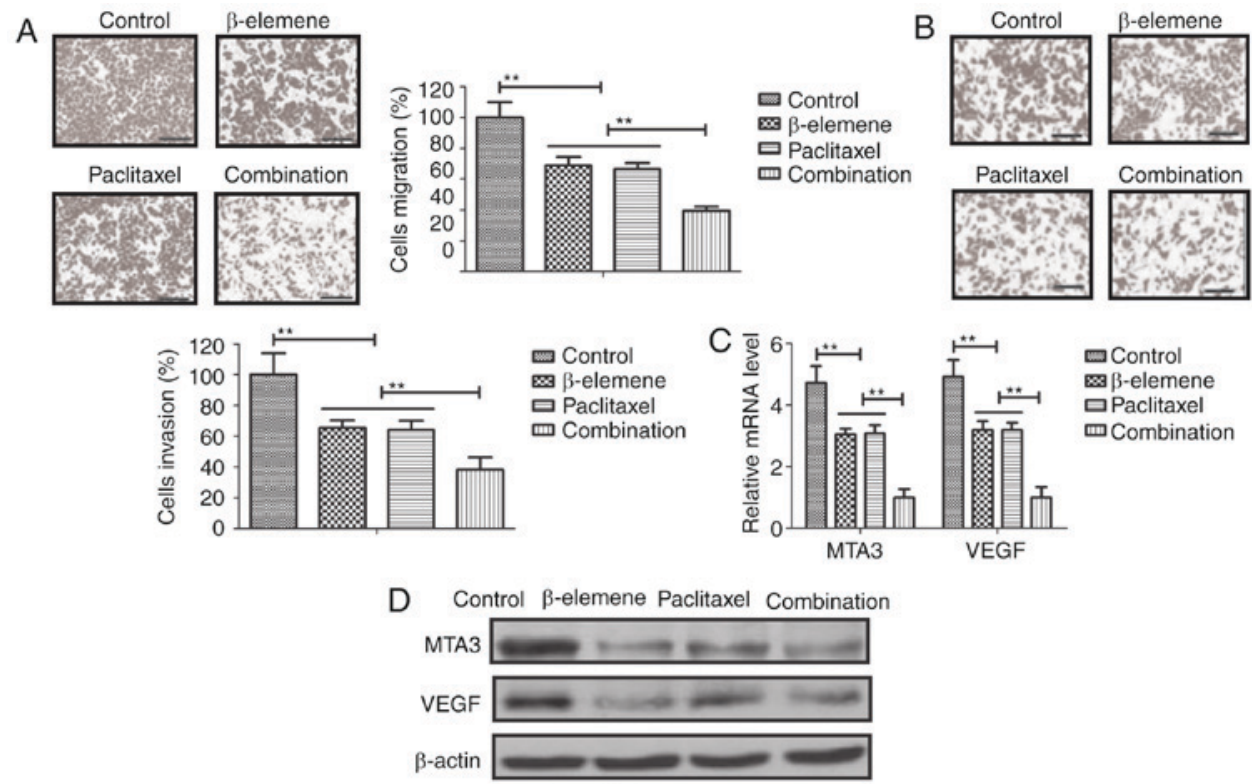

Figure 3. Treatment of $\beta$-elemene-paclitaxel inhibits migration and invasion of U-2OS cells. (A and B) $\beta$-elemene-paclitaxel treatment significantly inhibits migration (A) and invasion (B) of U-2OS cells in vitro. (C) Combined treatment of $\beta$-elemene-paclitaxel suppresses MTA3 and VEGF genes expression levels in U-2OS cells. (D) Combined treatment of $\beta$-elemene-paclitaxel suppresses MTA3 and VEGF protein expression levels in U-2OS cells, ${ }^{* *} \mathrm{P}<0.01$. MTA, metastasis-associated protein 3; VEGF, vascular endothelial growth factor.
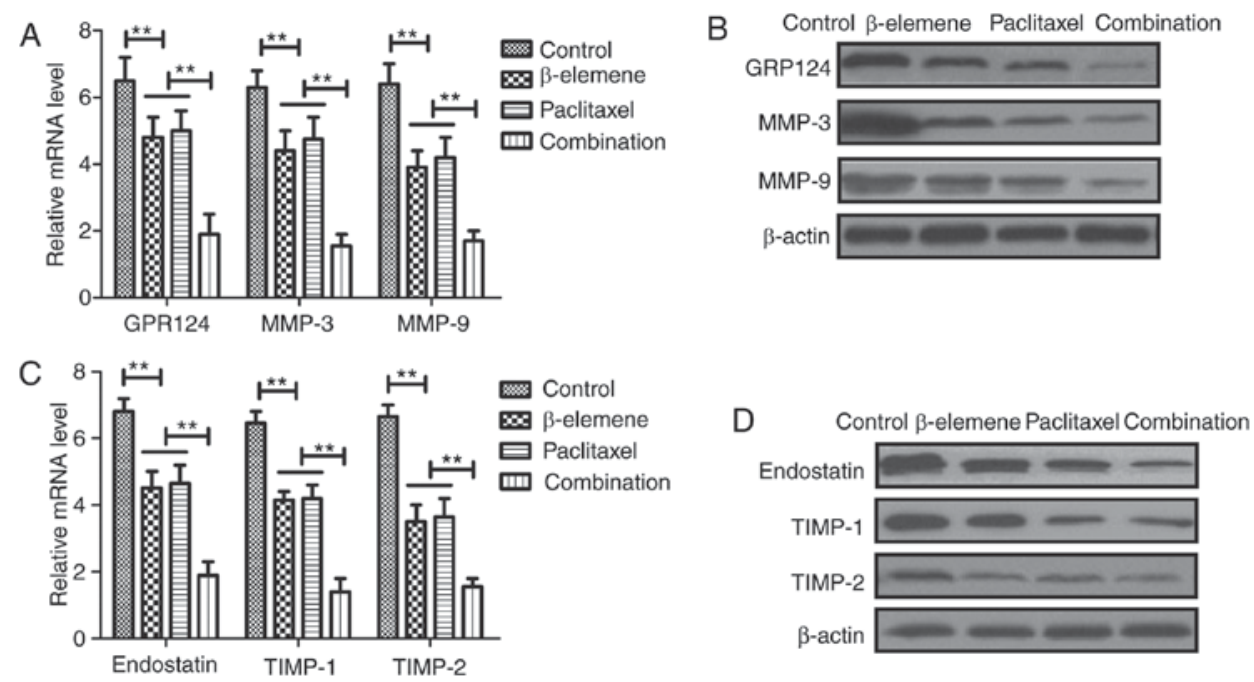

Figure 4. Treatment of $\beta$-elemene-paclitaxel regulates tumor angiogenesis-related gene expression in U-2OS cells. (A and B) Combined treatment of $\beta$-elemene-paclitaxel decreases GPR124, MMP-3 and MMP-9 gene (A) and protein (B) expression levels in U-2OS cells. (C and D) Combined treatment of $\beta$-elemene-paclitaxel combination increases endostatin, TIMP-1 and TIMP-2 mRNA (C) and protein (D) expression in U-2OS cells compared single treatment of $\beta$-elemene and paclitaxel. ${ }^{* *} \mathrm{P}<0.01$. GPR124, G-protein coupled receptor 124; MTA, metastasis-associated protein 3; TIMP, TIMP metallopeptidase inhibitor.

In vivo efficacy of $\beta$-elemene-paclitaxel in tumor-bearing mice. Finally, the in vivo efficacy of $\beta$-elemene-paclitaxel treatment was investigated in U-2OS-bearing mouse model. As shown in Fig. 5A, we showed that $\beta$-elemene-paclitaxel treatment significantly inhibited tumor growth compared to either $\beta$-elemene or paclitaxel treatment in a 24-day observation. Immunostaining demonstrated that $\beta$-elemene-paclitaxel treatment increased numbers of apoptotic body and GPR124 expression in tumor tissue compared to $\beta$-elemene or paclitaxel treatment group (Fig. 5B). Immunohistochemistry assays demonstrated that MMP-3 and VEGF expression levels were significantly increased in tumor tissue after $\beta$-elemene-paclitaxel treatment compared to $\beta$-elemene or paclitaxel treatment groups (Fig. 5C). 120-day observation indicated that $\beta$-elemene-paclitaxel treatment promoted survival rate of tumor-bearing mice (Fig. 5D). These results suggest that $\beta$-elemene-paclitaxel treatment is more effective in inhibition of $\mathrm{U}-2 \mathrm{OS}$ cells growth in vivo.

\section{Discussion}

Bone neoplasm is one kind of malignant tumors that cells occur in skeleton and its affiliates, which has been reported to present aberrant growth and migration in osseous tissues $(18,19)$. Evidences have indicated that systemic administration of paclitaxel can be regarded as efficient therapy for human 

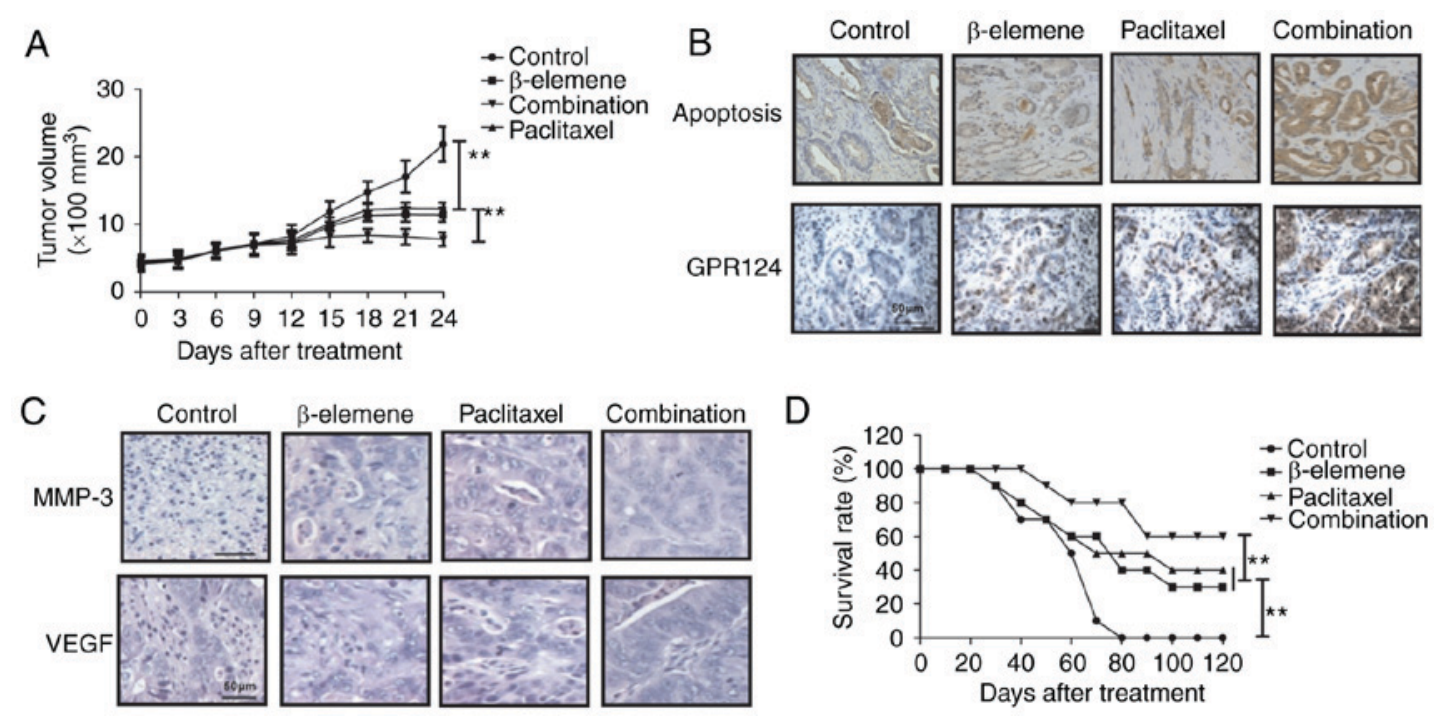

Figure 5. In vivo efficacy of $\beta$-elemene-paclitaxel in tumor-bearing mice. (A) $\beta$-elemene-paclitaxel treatment significantly inhibits tumor growth compared to either $\beta$-elemene or paclitaxel treatment in a 24 -day observation. (B) $\beta$-elemene-paclitaxel treatment increased numbers of apoptotic body and GPR124 expression in tumor tissue. (C) Combined treatment of $\beta$-elemene-paclitaxel decreases MMP-3 and VEGF expression levels in tumor tissue. (D) $\beta$-elemene-paclitaxel treatment prolongs survival time of tumor-bearing mice. ${ }^{* *} \mathrm{P}<0.01$. GPR124, G-protein coupled receptor 124; MTA, metastasis-associated protein 3; VEGF, vascular endothelial growth factor.

prostate cancer metastasis in bone of nude mice by simultaneous blockade of platelet-derived growth factor-receptor and epidermal growth factor-receptor signaling (20). In addition, antitumor effect of $\beta$-elemene for cancer cells is mediated by induction of cell cycle arrest and apoptotic cell death (21). In this study, we analyzed combined treatment of $\beta$-elemene and paclitaxel on bone neoplasm both in vitro and in vivo. Findings in this study showed that combined treatment of $\beta$-elemene and paclitaxel significantly inhibited growth and aggressiveness of U-2OS cells. In vitro and in vivo assays have demonstrated that $\beta$-elemene-paclitaxel treatment induced apoptosis and increased numbers of apoptotic body in tumor tissue compared to control groups.

Currently, $\beta$-elemene in combination with cisplatin has been regarded as a regimen for prostate cancer chemotherapy through regulation of apoptosis-related gene in tumor cells (22). Liu et al have suggested that $\beta$-elemene induces apoptosis as well as protective autophagy in human non-small-cell lung cancer A549 cells by inhibiting the activity of the PI3K/Akt/mTOR/p70S6K1 signalling pathway (23). Results in this study demonstrated that $\beta$-elemene could induce apoptosis of U-2OS cells by reduction of anti-apoptosis gene and increasing pro-apoptosis gene expression levels. Zhang et al also indicated that $\beta$-elemene blocks epithelial-mesenchymal transition in human breast cancer cell line MCF-7 through Smad3-mediated down-regulation of nuclear transcription factors (24). This study found that $\beta$-elemene inhibited tumor angiogenesis-related gene GPR124, VEGFR, MMP-3 and MMP-9 expression in U-2OS cells, while increased endostatin, TIMP-1 and TIMP-2 gene and protein expression in U-2OS cells. Reports have showed that GPR124 could affect migration and differentiation in endothelial cells in the generation and growth process of blood vessel. The role of GPR124 in endothelial cells regulates VEGF-induced tumor angiogenesis has been reported determined by the growth and the metastasis of in some tumors (25). Our results showed that $\beta$-elemene treatment led to decreasing of GPR124 and VEGF in U-2OS cells.

The combined treatments for human cancers could efficiently inhibit growth and prolong survival of cancer patients, including chemotherapeutic and antiangiogenic drugs, as well as targeting moieties (26). Previous studies have indicated that antiangiogenic antitumor activity of paclitaxel is efficiently for inhibiting breast cancer bone metastasis mouse model $(27,28)$. Although the emergence of adjuvant and neoadjuvant chemotherapy has been greatly improved the survival rate of patients with bone cancer, the morbidity and mortality rate of osteosarcoma is still keeping a steady increase (29). This research found that paclitaxel can inhibit the hematogenous metastasis and lymphatic metastasis of tumor via down-regulation for the protein level of GPR124, VEGF, MMP-3 and MMP-9 in U-2OS cells, which indicated that paclitaxel could inhibit the hematogenous metastasis and tumor growth through reducing vascular growth factor and its receptors. Importantly, we found that paclitaxel induced apoptosis of U-2OS cells and combined $\beta$-elemene and paclitaxel promoted apoptosis of $\mathrm{U}-2 \mathrm{OS}$ cells both in vitro and in vivo. Previous reports have showed that gene expression levels of MDR1, LRP and TS played important role in increasing the risk of drug-resistance in the treatment of human cancer (30-32). Interestingly, our results found that $\beta$-elemene decreased drug resistant genes expression levels of MDR1, LRP and TS in U-2OS cells, which contributed to apoptosis of U-2OS cells.

In conclusion, the combined treatment of $\beta$-elemene and paclitaxel enhanced the inhibition of U-2OS cells growth and aggressiveness, as well as increasing apoptosis both in vitro and in vivo. Especially, it is proved through the molecular biology experiment that the combined effect of $\beta$-elemene and paclitaxel can stimulate apoptosis and decrease the expression of GPR124, which further led to inhibition of growth and metastasis and arresting of cells cycle. Notably, tumor growth can be effectively inhibited through regulating the expression 
of GPR124 in bone cancer cells that contributed to long survival of tumor-bearing mice.

\section{Acknowledgements}

Not applicable.

\section{Funding}

No funding was received.

\section{Availability of data and materials}

The datasets used during the current study are available from the corresponding author on reasonable request.

\section{Authors' contributions}

$\mathrm{ZW}$ and YL constructed the experiments and organized the data, FZ, ZP, JH assisted in the analysis of data and ZW wrote the manuscript.

\section{Ethics approval and consent to participate}

The present study was approved by the Ethics Committee of the Nankai Hospital of Tianjin.

\section{Consent for publication}

Not applicable.

\section{Competing interests}

The authors declare that they have no competing interests.

\section{References}

1. Maeyama I: Review of bone tumor. Iryo 24 (Suppl): S227, 1970 (In Japanese).

2. Sanchez-Pareja A, Larousserie F, Boudabbous S, Beaulieu JY, Mach N, Saiji E and Rougemont AL: Giant cell tumor of bone with pseudosarcomatous changes leading to premature denosumab therapy interruption: A case report with review of the literature. Int J Surg Pathol 24: 366-372, 2016.

3. Huang L, Garcia-Manero G, Jabbour E, Goswami M, Routbort MJ, Medeiros LJ, Jorgensen JL and Wang SA: Persistence of immunophenotypically aberrant CD34+ myeloid progenitors is frequent in bone marrow of patients with myelodysplastic syndromes and myelodysplastic/myeloproliferative neoplasms treated with hypomethylating agents. J Clin Pathol pii: jclinpath-2016-203715, 2016.

4. Sever C, Abbott CL, de Baca ME, Khoury JD, Perkins SL, Reichard KK, Taylor A, Terebelo HR, Colasacco C, Rumble RB and Thomas NE: Bone marrow synoptic reporting for hematologic neoplasms: Guideline from the college of American pathologists pathology and laboratory quality center. Arch Pathol Lab Med 140: 932-949, 2016.

5. Lekovic D, Gotic M, Skoda R, Beleslin-Cokic B, Milic N, Mitrovic-Ajtic O, Nienhold R, Sefer D, Suboticki T, Buac $\mathrm{M}$, et al: Bone marrow microvessel density and plasma angiogenic factors in myeloproliferative neoplasms: Clinicopathological and molecular correlations. Ann Hematol 96: 393-404, 2017.

6. Song T, Zhang X, Fang M, Zhao R and Wu S: Long-term results of definitive concurrent chemoradiotherapy using paclitaxel plus oxaliplatin in unresectable locally advanced esophageal cancer: A prospective phase II trial. Cancer Med 5: 3371-3377, 2016.
7. Fukuchi M, Mochiki E, Ishiguro T, Ogura T, Sobajima J, Kumagai Y, Ishibashi K and Ishida H: Efficacy of Nab-Paclitaxel as second-line chemotherapy for unresectable or recurrent gastric cancer. Anticancer Res 36: 6699-6703, 2016.

8. Garon EB, Neidhart JD, Gabrail NY, de Oliveira MR, Balkissoon J and Kabbinavar F: A randomized Phase II trial of the tumor vascular disrupting agent CA4P (fosbretabulin tromethamine) with carboplatin, paclitaxel, and bevacizumab in advanced nonsquamous non-small-cell lung cancer. Onco Targets Ther 9: 7275-7283, 2016.

9. Kreger BT, Johansen ER, Cerione RA and Antonyak MA: The enrichment of survivin in exosomes from breast cancer cells treated with paclitaxel promotes cell survival and chemoresistance. Cancers 8: pii: E111, 2016.

10. Liu X, Gao Y, Shen J, Yang W, Choy E, Mankin H, Hornicek FJ and Duan Z: Cyclin-dependent kinase 11 (CDK11) is required for ovarian cancer cell growth in vitro and in vivo, and its inhibition causes apoptosis and sensitizes cells to paclitaxel. Mol Cancer Ther 15: 1691-1701, 2016.

11. Awasthi N, Scire E, Monahan S, Grojean M, Zhang E, Schwarz MA and Schwarz RE: Augmentation of response to nab-paclitaxel by inhibition of insulin-like growth factor (IGF) signaling in preclinical pancreatic cancer models. Oncotarget 7: 46988-47001, 2016.

12. Wang H, Li D, Li X, Ou X, Liu S, Zhang Y, Ding J and Xie B: Mammalian target of rapamycin inhibitor RAD001 sensitizes endometrial cancer cells to paclitaxel-induced apoptosis via the induction of autophagy. Oncol Lett 12: 5029-5035, 2016.

13. Şakalar Ç, İzgi K, İskender B, Sezen S, Aksu H, Çakır M, Kurt B, Turan $\mathrm{A}$ and Canatan $\mathrm{H}$ : The combination of thymoquinone and paclitaxel shows anti-tumor activity through the interplay with apoptosis network in triple-negative breast cancer. Tumour Biol 37: 4467-4477, 2016.

14. Wang B, Peng XX, Sun R, Li J, Zhan XR, Wu LJ, Wang SL and Xie T: Systematic review of $\beta$-elemene injection as adjunctive treatment for lung cancer. Chin J Integr Med 18: 813-823, 2012.

15. Liu J, Zhang Y, Qu J, Xu L, Hou K, Zhang J, Qu X and Liu Y: $\beta$-Elemene-induced autophagy protects human gastric cancer cells from undergoing apoptosis. BMC Cancer 11: 183, 2011.

16. Li QQ, Wang G, Huang F, Banda M and Reed E: Antineoplastic effect of beta-elemene on prostate cancer cells and other types of solid tumour cells. J Pharm Pharmacol 62: 1018-1027, 2010.

17. Oberhaus SM:TUNEL and immunofluorescence double-labeling assay for apoptotic cells with specific antigen(s). Methods Mol Biol 218: 85-96, 2003.

18. Li YF, Cha TL, Jin JS and Yu CP: Chromophobe renal cell carcinoma with osteosarcoma differentiation: Case report and literature review. Urol Int 85: 470-474, 2010.

19. Kager L, Pötschger U and Bielack S: Review of mifamurtide in the treatment of patients with osteosarcoma. Ther Clin Risk Manag 6: 279-286, 2010.

20. Kim SJ, Uehara H, Yazici S, Langley RR, He J, Tsan R, Fan D, Killion JJ and Fidler IJ: Simultaneous blockade of platelet-derived growth factor-receptor and epidermal growth factor-receptor signaling and systemic administration of paclitaxel as therapy for human prostate cancer metastasis in bone of nude mice. Cancer Res 64: 4201-4208, 2004.

21. Wang G, Li X, Huang F, Zhao J, Ding H, Cunningham C, Coad JE, Flynn DC, Reed E and Li QQ: Antitumor effect of beta-elemene in non-small-cell lung cancer cells is mediated via induction of cell cycle arrest and apoptotic cell death. Cell Mol Life Sci 62: 881-893, 2005.

22. Li QQ, Wang G, Reed E, Huang L and Cuff CF: Evaluation of cisplatin in combination with $\beta$-elemene as a regimen for prostate cancer chemotherapy. Basic Clin Pharmacol Toxicol 107: 868-876, 2010.

23. Liu J, Hu XJ, Jin B, Qu XJ, Hou KZ and Liu YP: $\beta$-Elemene induces apoptosis as well as protective autophagy in human non-small-cell lung cancer A549 cells. J Pharm Pharmacol 64: 146-153, 2012.

24. Zhang X, Li Y, Zhang Y, Song J, Wang Q, Zheng L and Liu D: Beta-elemene blocks epithelial-mesenchymal transition in human breast cancer cell line MCF-7 through Smad3-mediated down-regulation of nuclear transcription factors. PLoS One 8: e58719, 2013.

25. Wang Y, Cho SG, Wu X, Siwko S and Liu M: G-protein coupled receptor 124 (GPR124) in endothelial cells regulates vascular endothelial growth factor (VEGF)-induced tumor angiogenesis. Curr Mol Med 14: 543-554, 2014. 
26. Airley R: Lab reports and cat scans: Can veterinary oncology guide our way to new treatments for human cancers? Future Med Chem 4: 1391-1394, 2012

27. Ding D and Kong WM: Analysis of relative factors of bone marrow suppression after chemotherapy with carboplatin and paclitaxel on the patients with ovarian cancer. Zhonghua fu chan ke za zhi 46: 188-192, 2011 (In Chinese).

28. Miller K, Eldar-Boock A, Polyak D, Segal E, Benayoun L, Shaked Y and Satchi-Fainaro R: Antiangiogenic antitumor activity of HPMA copolymer-paclitaxel-alendronate conjugate on breast cancer bone metastasis mouse model. Mol Pharm 8: 1052-1062, 2011

29. He H, Ni J and Huang J: Molecular mechanisms of chemoresistance in osteosarcoma (Review). Oncol Lett 7: 1352-1362, 2014.

30. Chen JR, Jia XH, Wang H, Yi YJ, Wang JY and Li YJ: Timosaponin A-III reverses multi-drug resistance in human chronic myelogenous leukemia K562/ADM cells via downregulation of MDR1 and MRP1 expression by inhibiting PI3K/Akt signaling pathway. Int J Oncol 48: 2063-2070, 2016.
31. Kurata M, Hasegawa M, Nakagawa Y, Abe S, Yamamoto K, Suzuki K and Kitagawa M: Expression dynamics of drug resistance genes, multidrug resistance 1 (MDR1) and lung resistance protein (LRP) during the evolution of overt leukemia in myelodysplastic syndromes. Exp Mol Pathol 81: 249-254, 2006.

32. Ijichi K, Adachi M, Ogawa T, Hasegawa Y and Murakami S: Cell-cycle distribution and Thymidilate Synthatase (TS) expression correlate with 5-FU resistance in head and neck carcinoma cells. Anticancer Res 34: 2907-2911, 2014.

(i) (3) This work is licensed under a Creative Commons Attribution-NonCommercial-NoDerivatives 4.0 International (CC BY-NC-ND 4.0) License. 